\title{
Hexose Uptake and Transport in Polymorphonuclear Leukocytes from Patients with Glycogen Storage Disease Ib
}

\author{
RUTH POTASHNIK, ARIE MORAN, SHIMON W. MOSES, NIZA PELEG, AND NAVA BASHAN \\ Pediatric Research Laboratory (Clinical Biochemistry Unit) (R.P., S.W.M., N.P., N.B.] and \\ Unit of Physiology [A.M.), Soroka Medical Center and Faculty of Health Sciences, \\ Ben-Gurion Universily of the Negev, Beer-Sheva, Israel
}

\begin{abstract}
Neutrophil functions and glucose metabolism are known to be impaired in glycogen storage disease (GSD) Ib patients. The uptake of nonmetabolizing glucose analognes into polymorphonuclear leukocytes (PMN) of GSD Ib patients was studied. 2-Deoxyglucose (2-DOG) and 3-O-methylglucose are transported across the cell membrane by facilitated diffusion mediated by the glucose transporter. Because 2-DOG is phosphorylated within the cell, its uptake rate reflects hexose transport as long as phosphorylation is not rate-limiting. These conditions prevail only at low 2 -DOG concentrations. Transport of $5 \mu \mathrm{M}$ DOG into GSD Ib patient PMN was found to be similar to controls $\left(4.3 \pm 0.5\right.$ and $4.65 \pm 1.77 \mathrm{pmol} / \mathrm{min} \times 10^{6}$, respectively). In contrast, $2-D O G$ uptake at high concentrations $(2 \mathrm{mM})$ decreased by $70 \%$ in patient PMN compared with control cells $(0.17 \pm 0.06$ and $0.51 \pm 0.11 \mathrm{nmol} /$ min $\times 10^{6}$, for patients and controls, respectively). Transport of 3-O-methylglucose (a glucose analogue that does not undergo intracellular phosphorylation) was not different in patient PMN compared with controls (1.86 \pm 0.53 and $2.19 \pm 0.30 \mathrm{nmol} / \mathrm{min} \times 10^{6}$, respectively). Hexose monophosphate shunt activity in PMN of GSD Ib patients at a glucose concentration of $2 \mathrm{mM}$ was $43 \%$ of control values, whereas at $10 \mu \mathrm{M}$ it was similar to controls. Taken together, these results suggest that the defect in glucose uptake and metabolism found in GSD Ib patient PMN is due to an impairment in hexose phosphorylation rather than in a reduction in the transmembrane glucose transport activity. (Pediatr Res 28: 19-23, 1990)
\end{abstract}

\section{Abbreviations}

GSD, glycogen storage disease

PMN, polymorphonuclear leukocyte

3-O-MG, 3-O-methylglucose

2-DOG, 2-deoxyglucose

G6P, glucose-6-phosphate

HMP, hexose-monophosphate

KRP, Krebs Ringer phosphate

FMLP, formyl-methionyl-leucyl-phenylalanine

GSD Ib (McKusick 23222) is a metabolic disease caused by a defect in the translocase for G6P in the liver microsomal membrane $(1,2)$. As a result, hepatic glucose-6-phosphatase in GSD

Received December 27, 1989: accepted March 14, 1990.

Correspondence: Nava Bashan, Ph.D. Clinical Biochemical Unit, Soroka Medical Center, Ben-Gurion University of the Negev, Beer-Sheva 84105 , Israel.

Supported by funds of the chief scientist's office. Ministry of Health. Israel.
Ib patients is nonfunctional in vivo. GSD Ia (McKusick 23220) is caused by a deficiency of the G6Pase activity. Patients with GSD Ib are often neutropenic and prone to recurrent infections; otherwise, the clinical features of GSD Ib are indistinguishable from GSD Ia. There is increasing evidence of functional defects in the neutrophils of GSD Ib patients that limit their ability to destroy invading microorganisms. Defects in random and direct cell migration, extra phagocytotic respiration, chemotaxis bactericidal activity, and calcium mobilization in response to FMLP was found in the patient neutrophils $(3-10$, and Kilpatrick $L$, Garty BZ, Lunquist KF, Stanley CA, Baker L, Douglas SD, Korchak HM, personal communication).

A decreased rate of 2-DOG uptake into PMN collected from GSD Ib patients was previously demonstrated $(6,8,10) .2-\mathrm{DOG}$ is widely used as a nonmetabolizable glucose analogue to study the transport of hexose in various cell types. 2.DOG enters the cell by way of facilitated transport similar to glucose, and it is phosphorylated within the cell to 2-deoxyglucose-6-phosphate. The phosphorylated analogue is not metabolized further and is trapped within the cell, since it can no longer traverse the cell membrane $(11-13)$. Thus, uptake of $2-D O G$ reflects transport as long as the hexokinase activity does not become rate-limiting, a condition that is obtained only at low 2-DOG concentrations (14).

Another analogue of glucose is $3-0-\mathrm{MG}$. This analogue is transported across PMN membrane by the glucose transporter, but, unlike 2-DOG, it is not further metabolized within the cells. Therefore, it can be used for direct assessment of hexose transport across PMN cell membrane $(15,16)$.

Our study suggests that the defect in glucose uptake into GSD Ib neutrophils is derived from impairment in hexose phosphorylation rather than a direct alteration in transmembrane glucose transport.

\section{MATERIALS AND METHODS}

Patients. GSD Ib was diagnosed in liver biopsies by a high latency (i.e. low activity) of glucose-6-phosphatase in fresh homogenate and normal activity in disrupted microsomes $(17)$. The six GSD Ib patients suffered from numerous infections. The clinical and therapeutic data of the patients and one GSD Ia patient are summarized in Table 1. Studies of PMN were performed with preparations at an initial cell count of 600 to 1500 cells $/ \mathrm{mm}^{3}$.

Cell Preparation. PMN from patients with GSD Ib and from healthy donors were separated from heparinized venous blood by the Ficoll-Hypaque centrifugation method (6). Briefly, one volume of fresh blood was mixed with two volumes of $3 \%$ dextran in $0.85 \% \mathrm{NaCl}$. After one hour at $4^{\circ} \mathrm{C}$, the supernatant was layered on top of Ficoll-Hypaque (Pharmacia Inc., Piscataway, NJ) at a volume ratio of $6 \mathrm{~mL}$ of cell suspension to $3 \mathrm{~mL}$ 
Table 1. Laboratory data of patients studied

\begin{tabular}{|c|c|c|c|c|c|c|c|}
\hline & \multicolumn{6}{|c|}{ GSD Ib patients } & \multirow{2}{*}{ 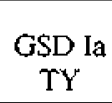 } \\
\hline & LS & $\mathrm{AA}$ & NT & RA & $\mathrm{BM}$ & SS & \\
\hline Age $(y)$ & 13 & 4 & 3 & $3 / 12$ & 2 & 5 & 3 \\
\hline Uric acid (mg/dL) & 4.7 & 7.0 & 5.7 & 4.5 & 7.5 & 7.3 & 7.0 \\
\hline Cholesterol (mg/dL) & 98 & 128 & 173 & 112 & 142 & 129 & 230 \\
\hline Serum glutamic oxaloacetic transaminase (IU) & 54 & 67 & 120 & 33 & 35 & 42 & 62 \\
\hline PMN (\% of total leukocytes) & 24 & 27 & 15 & 7 & 6 & 17 & 28 \\
\hline
\end{tabular}

of Ficoll. After centrifugation for $30 \mathrm{~min}$ at $5^{\circ} \mathrm{C}$ at $800 \times \mathrm{g}$, the pellet was collected for PMN preparation. Contaminating red cells were removed by the addition of $6 \mathrm{~mL}$ distilled $\mathrm{H}_{2} \mathrm{O}$ for 20 $\mathrm{s}$, and isotonicity was restored by the addition of $2 \mathrm{~mL} 3.5 \%$ $\mathrm{NaCl}$.

Cells were suspended in KRP buffer, counted in a hemocytometer, and adjusted to $30-40 \times 10^{6} \mathrm{cells} / \mathrm{mL}$. The final preparations contain $>85 \%$ PMN in both patients and control samples.

Transport Studies of Glucose Analogues into PMN. 2-DOG transport. A total of $1-2 \times 10^{6}$ purified PMN suspended in 45 $\mu \mathrm{L}$ KRP were incubated for $15 \mathrm{~min}$ at $37^{\circ} \mathrm{C}$ in a $4.5 \mathrm{~mL}$ roundbottomed mini scintillation vial (14). 2-DOG uptake was initiated by adding $15 \mu \mathrm{L} \mathrm{KRP}$ buffer containing $1-{ }^{3} \mathrm{H}-2-\mathrm{DOG}[1.48$ $\mathrm{MBq} / \mathrm{mL}(40 \mu \mathrm{Cl} / \mathrm{mL})]$ in concentrations indicated in figure legends. Uptake (linear up to $5 \mathrm{~min}$ ) was stopped after $2 \mathrm{~min}$ by the addition of $2 \mathrm{~mL}$ cold $0.85 \% \mathrm{NaCl}$ containing $0.3 \mathrm{mM}$ phloretin, and $0.1 \mu \mathrm{M} \mathrm{HgCl}_{2}$. The samples were centrifuged at $3000 \times \mathrm{g}$ for $3 \mathrm{~min}$ and the pellets were washed twice by centrifugation with $2 \mathrm{~mL}$ cold $0.85 \% \mathrm{NaCl}$. The washed pellets were examined for radioactivity in instagel scintillation fluid, using a Packard tricarb spectrometer (Packard Instrument Co., Inc., Downers Grove, IL).

3-O-MG Transport. Transport of 3-O-MG during a $20 \mathrm{~s}$ time period was measured in a similar way to 2-DOG transport. Uptake was initiated by adding $15 \mu \mathrm{L}$ KRP buffer containing 3O-MG $[5.5 \mathrm{MBq} / \mathrm{mL}(150 \mu \mathrm{Ci} / \mathrm{mL})]$ at the concentrations indicated in the figure legends. The subsequent procedure was the same as described for 2-DOG transport.

Phosphorylation of 2-deoxvglucose. $10^{6} \mathrm{PMN}$ were incubated at $37^{\circ} \mathrm{C}$ in a final volume of $60 \mu \mathrm{L}$ containing $2 \mathrm{mmol} / \mathrm{L}{ }_{-}{ }^{3} \mathrm{H}-$ $2-\mathrm{DOG}[7 \mathrm{KBq} / \mathrm{mL}(0.2 \mu \mathrm{Ci})]$. Cells were washed as described for 2-DOG. The final pellets were suspended in $1 \mathrm{~mL}$ water and boiled for $5 \mathrm{~min}$ in a water bath. Subsequently, denatured protein was removed by centrifugation. The supernatant was applied to a column of Dowex-1-Cl-resin $(10 \mathrm{~cm} \times 1 \mathrm{~cm})$ as described before (11). The column was washed with $10 \mathrm{~mL}$ water to elute free $2-\mathrm{DOG}$ and $10 \mathrm{~mL} 0.5 \mathrm{~mol} / \mathrm{L} \mathrm{HCl}$ to remove 2-deoxyglucose-6-phosphate. Samples of $1 \mathrm{~mL}$ from each fraction were measured for radioactivity.

Activity of the HMP Shunt. The activity of the HMP shunt was determined by a modification of the method described by Newburgh et al. ([8). Briefly, PMN were suspended in KRP $\left(10^{\circ}\right.$ cells $/ \mathrm{mL})$ with $\left[1-{ }^{14} \mathrm{C}\right]$-glucose $[18 \mathrm{KBq} / \mathrm{mL}(0.5 \mu \mathrm{Ci} / \mathrm{mL})]$ at the concentrations indicated in Table 4 , and $1 \mathrm{mmol} / \mathrm{L}$ methylene blue. Incubation at $37^{\circ} \mathrm{C}$ for $1 \mathrm{~h}$ was performed in sealed tubes with a central well containing filter paper impregnated with $100 \mu \mathrm{L}$ of hyamine-hydroxide. At the end of the incubation period, $0.5 \mathrm{~mL}_{\text {of }} \mathrm{H}_{2} \mathrm{SO}_{4}(2 \mathrm{~mol} / \mathrm{L})$ was added to stop the reaction and to release ${ }^{14} \mathrm{CO}_{2}$ from the solution. The tubes were subsequently shaken for $30 \mathrm{~min}$. The filter paper was removed and placed in vials filled with a toluene-based scintillation fluid, and radioactivity was determined in a tricarb spectrometer.

Statistical Analysis. Data are presented as the mean \pm SD. For each assay, not less than three separate observations were made in independent experiments. The $t$ test was used to compare the mean value of control assays with those of GSD Ib patients ( $n=$ 6).

Materials. D-1- ${ }^{3} \mathrm{H}-2-D e o x y g l u c o s e, 3-\mathrm{O}-$ methyl-D-[1- $\left.{ }^{3} \mathrm{H}\right] \mathrm{glu}-$ cose, and $1{ }^{14} \mathrm{C}$-glucose were purchased from Amersham Co., Buckinghamshire, UK. All other chemicals were purchased from Sigma Chemical Co., St. Louis, MO.

\section{RESULTS}

The rate of 2-DOG and 3-O-MG uptake by PMN of GSD Ib and GSD Ia patients under saturating concentrations, as compared with controls, is demonstrated in Table 2. 2-DOG transport in PMN from individuals in different age groups (from $5 \mathrm{~d}$ to $40 \mathrm{y}$ old) was the same (9). Uptake of $2-\mathrm{DOG}$ is reduced to $30 \%$ in the PMN of GSD Ib patients as compared with GSD Ia patients or controls. By contrast, no significant difference was observed in the rate of 3-O-MG transport between patient and control PMN.

Figure 1 shows zero trans entry (all sugar analogues were initially only outside the cell) of 3-O-MG and 2-DOG as a function of concentration. Both 2-DOG and 3-O-MG are taken up into PMN by facilitated diffusion. The uptake of both sugars follows saturation type kinetics, with $\mathrm{Km}$ values of $0.6 \mathrm{mM}$ and $5 \mathrm{mM}$ and $V_{\max }$ of $0.51 \pm 0.11$ and $2.19 \pm 0.3 \mathrm{nmol} / \mathrm{min} \times 10^{6}$ for $2-\mathrm{DOG}$ and $3-\mathrm{O}-\mathrm{MG}$, respectively. The different kinetic constants observed could be due to different affinities of the

Table 2. 2-deoxyglucose and 3-O-methylglucose uplake in human $P M N$ of GSD $I a$ and $G S D$ Ib patients and normal controls*

\begin{tabular}{lcc}
\hline & $\begin{array}{c}\text { 2-deoxyglucose } \\
\text { uptake } \\
\text { nmol } / 10^{6} \text { cells } \times \text { min }\end{array}$ & $\begin{array}{c}\text { 3-O-methylglucose } \\
\text { uptake }\end{array}$ \\
\hline Controls & $0.51 \pm 0.11(21) \dagger$ & $2.19 \pm 0.30(7) \dagger$ \\
GSD Ia patients & $0.31 \pm 0.12(4) \dagger$ & $1.8 \pm 0.4(4) \dagger$ \\
D valuef & $\mathrm{NS}$ & $\mathrm{NS}$ \\
GSD Ib patients & $0.14 \pm 0.02(9) \S$ & $1.39 \pm 0.42(4) \S$ \\
NT & $0.08 \pm 0.03(6) \S$ & $1.76 \pm 1.02(6) \S$ \\
LS & $0.22 \pm 0.01(3) \S$ & $2.44 \pm 0.62(3) \S$ \\
AA & $0.18 \pm 0.06(3) \S$ & $\mathrm{ND} \|$ \\
SS & $0.18(2) \S$ & $\mathrm{ND} \|$ \\
BM & $0.26(1) \S$ & $\mathrm{ND \|}$ \\
RA & $0.17 \pm 0.06(6) \S$ & $1.86 \pm 0.53(3) \S$ \\
Overall mean lb patients & 0.05 & $\mathrm{NS}$ \\
\hline valued & $<0.05$ &
\end{tabular}

* The initial rates of 2-DOG and 3-O-MG transport were measured as described in Materials and Methods at saturating concentrations of substrate (2-DOG at $2 \mathrm{mM}$ and 3-O-MG at $15 \mathrm{mM}$ ).

\$ Number of controls and GSD la patients.

$\$ t$ test comparing mean of control values with mean of GSD la patients.

$\S 0$, number of experiments performed.

II ND, not determined.

I $/$ test comparing mean of control values with mean of GSD Ib patients. 